\title{
Gendered Rights in the Post-2015 Development and Disasters Agendas
}

\author{
Sarah Bradshaw
}

\begin{abstract}
This article explores how, 20 years after the Beijing conference, women's rights are being discussed within processes to develop a post-2015 sustainable development agenda and the parallel international disaster risk reduction framework. It is based on analysis of documents produced to date from the various processes, and also personal experience of seeking to influence both the post-2015 development and disaster agendas. It highlights how attempts to marry the environmental and development agendas reveal a continued problematic conceptualisation of sexual and reproductive rights. It suggests that in gender terms, while the post-2015 development agenda and the related Sustainable Development Goals (SDGs) are over-ambitious to the point of being mere rhetoric, gender rhetoric is yet to enter the international disaster risk reduction discourse. This, the article argues, coupled with the continued conceptualisation of disasters as outside mainstream development, has further negative implications for the recognition and fulfilment of women's rights.
\end{abstract}

\section{Introduction}

The year 2015 has become a milestone year for gender and development. Beijing+20 coincides with the culmination of the process, initiated by the Rio +20 meeting in 2012 and the 2010 meeting to review the Millennium Development Goals (MDGs), to establish a set of Sustainable Development Goals (SDGs). It is also an important year for the wider 'sustainability' agenda as the United Nations Framework Convention on Climate Change (UNFCCG) comes of age, celebrating its 21st Conference of the Parties (COP) with the promise of a legally binding resolution around climate change. The outcomes of extreme climatic events have also been addressed in 2015 with the adoption in March of the Sendai Framework for Disaster Risk Reduction.

This article considers the extent to which women's rights are being promoted within these wider environmental sustainability and development processes, the extent to which they reflect and build on the agreements made in Beijing, and the extent to which they represent joined up thinking around promoting women's rights. It draws on analysis of documents produced to date from the various processes, and also experience of seeking to influence how gender is incorporated into the SDGs via work with the UN Sustainable Development Solutions Network (SDSN) initiative, and attempts to engender the post-2015 disaster risk reduction agenda through work with the Women's Major Group (WMG).

\section{The post-2015 sustainable development process}

After the first Rio meeting/Earth Summit in 1992 gender activists and women's movements highlighted how, given the approach adopted, the notion of 'sustainable development' was a huge contradiction. In 2012 the Rio+20 conference brought international attention back to the concept, and saw it defined in relation to poverty and inequality. The outcome document - The Future We Want (United Nations 2012) - also has a clear rights rhetoric, and within this there is mention of women's rights, including economic rights and also sexual and reproductive health and rights. The latter is discussed in relation to the implementation of the Beijing Declaration and Platform for Action (BPfA), and the International Conference on Population and Development (ICPD) Programme of Action.

The main outcome of the Rio+20 conference was the establishment of a new process to further the pursuit of a sustainable development agenda via an 'inclusive and transparent intergovernmental process' with a view to developing a set of global SDGs.

To this end an Open Working Group (OWG) was established in January 2013 and included 70 member states in 30 multi-constituency or 'shared' seats. 
The process established by Rio +20 to develop a set of new goals paralleled that initiated after the UN General Assembly's High-level Plenary Meeting on the MDGs in 2010 (the MDG Summit). The MDG Summit proposed to advance the development agenda beyond 2015 and to this end, a High Level Panel (HLP) of Eminent Persons was established in July 2012. The 27-member HLP brought together leading representatives from civil society, the private sector, academia and local and national governments and was charged with submitting a report containing its vision and recommendations on a global development agenda to the Secretary General in May 2013.

The MDG Summit outcome document gave an early indication of what the new set of goals might look like in gender terms. Unlike the MDGs, the review document does mention sexual and reproductive health, and makes many mentions of rights, noting, for example, how violence undermines the full enjoyment of all human rights for women and girls. While such language suggests an advance on the MDGs, there are still issues raised by the rights discourse. For example, it promotes gender equality as having a 'multiplier effect' and women's rights then are presented largely as a development 'enabler'.

Of the two processes set up to define the post2015 agenda, the HLP was the first to produce its report including a set of 12 illustrative goals, which were then considered by the OWG as it began its discussions. The OWG expanded the number of goals to 17. After much rumour that the Secretary General would reduce the number of goals to 15 or possibly even to ten, his Synthesis Report The Road to Dignity (United Nations 2014) published in early December 2014 left them as they were. The OWG goals then provided the basis for intergovernmental negotiations to agree the final set of SDGs.

Before considering the post-2015 agenda, and attempts to engender that agenda, one other actor in the process needs to be introduced. While the SDG process 'began' with the HLP, which informed the OWG, which in turn formed the basis for intergovernmental negotiations, the HLP itself was informed by a number of processes and entities. This included inputs from the newly formed SDSN. Launched in 2012 with Jeffrey Sachs as its director, the SDSN seeks to 'mobilise scientific and technological knowledge' to focus on the 'challenges of sustainable development'. It has a leadership council of over 60 members, drawn from universities, thinktanks, government ministries, private corporations and NGOs. A number of the council members also chair one of the SDSN thematic groups, with Thematic Group Three (TG03) seeking to explore the 'Challenges of Social Inclusion', focusing on gender, inequalities and human rights.

The SDSN argue that planetary boundaries should not be presented as an excuse not to work for the development of all countries. They also suggest, however, that a 'business as usual' approach post-2015 will result in growing inequalities, little 'development', and many regions and peoples failing to improve their wellbeing. The SDSN then seek to find a balance between demands for development and concerns around sustainability, to balance respect for the planet with the promotion of rights. It brings together the 'scientific' and social science communities, those working on environmental and those on equality issues.

A proactive network, the SDSN fed into the HLP process directly through the production of background reports and also produced its own set of illustrative goals published in its 'Action Agenda' in May 2013. Around the same time, and towards the end of the HLP process, the panel called for a fivepage background report on 'Women and Economic Development' to inform its discussions. It turned to the SDSN TG03 to produce this. As the co-chair of TG03 is my Dean of School, this is when I was drawn into the post-2015 process. While having written critiques of the MDGs and being cynical of any process to design a new set of goals to replace them, I took up the task of writing the five-page background report for the HLP.

\section{Engendering the post-2015 sustainable development process}

The HLP asked that the background report on 'Women and Economic Development' address three questions: What is the evidence base to support investing in women? What are the current constraints on realising the full potential of women in the process of economic development? What are the priority areas of intervention necessary to unblock these constraints? As can be seen from the questions the focus was on economic not social development, constructing women as a productive asset and with an aim to overcome the 'obstacles' to utilising this 'potentially productive' resource. The focus on 'investing in women' rather than on promoting gender equality suggests an efficiency rather than an equality approach - 'business as usual' then, where gender is concerned. 
Building on the many years of sustained critique from activists and academics alike of such an approach, the background report sought to address and redress this instrumentalism and present gendered rights as a goal in themselves (see Bradshaw, Castellino and Diop 2013). This echoed the discourse of many women's groups and movements, including UN Women, already seeking to influence the process. On first review these efforts do seem to have had an effect as the HLP report presents a clear gender equality rhetoric. Illustrative Goal 2, 'Empower girls and women to achieve gender equality', includes specific mention of Violence Against Women and Girls (VAWG) for example, and also mention of 'harmful practices' such as child marriage. More broadly, it calls for the elimination of discrimination in political, economic and public life, and equality for women in terms of land, business and banking. This, coupled with the pledge to ensure sexual and reproductive health and rights in Goal 4, suggests a clear advancement on the MDGs. This is made stronger still by the call for sex-disaggregated data across a range of the goals, suggesting an attempt to 'mainstream' gender across the agenda.

In June 2013 I was invited by the Secretariat of the HLP to participate in what was described as an international workshop aiming to 'garner the main critiques from the academic community as well as delineate the key contours of the post-2015 research agenda'. The small number of participants seemed to be only those who had written background reports. During the event the issue of the extent to which the gender rhetoric of the document could be made a reality was raised. The response was interesting. It suggested a clear strategy, at least from the authors of the document/the Secretariat of the Panel, to present an (overly) ambitious agenda as a starting point for negotiations. While laudable, ambitious targets raise issues over the means to achieve them. The HLP agenda would, to gender activists, suggest a call for radical change, one which questions structural inequalities and patriarchal structures. Given the co-chair of the HLP was UK Prime Minister David Cameron, it might be assumed this type of change was not something envisaged by them. An ambitious gender rhetoric such as this may have two outcomes - it may raise suspicions among gender activists or, if accepted on face value, may set up a contradiction in expectations from the start. This, of course, would only be an issue if the radical agenda survived the process and the move to the OWG and beyond.

Before considering the resultant move from the HLP to the OWG process, a short detour is needed to visit the SDSN initiative and the illustrative goals they produced, as these too have been an important input into the SDG design process. The SDSN not only sought to shape the HLP goals but also produced its own set of ten goals as part of what it describes as an 'integrated, concise, science based and action oriented agenda' for sustainable development. The goals were finalised before my engagement with the SDSN and on reading their agenda the lack of a standalone gender goal came as somewhat of a surprise. Goal 4 'Achieve gender equality, social inclusion and human rights for all' does promote gender equality, and has a target specifically focused on preventing and ending VAWG. However, gender equality is here located within the wider aim to reduce inequalities and discrimination by gender, age, ethnicity and sexuality, among others. The SDSN rhetoric suggests that this is an attempt to reflect how gender interacts with other characteristics to build inequalities and that discriminations may be multiple. Gender is not confined to only one goal and instead it is suggested that it will be 'mainstreamed' throughout the SDSN goals, not only via a call for sex-disaggregated data, but also via the construction of more integrated, 'joined up' goals.

The SDSN stresses that there is a 'headline' gender goal, while highlighting that to address intersecting and multiple sites of oppression demands integrated and inclusive goals. This more holistic approach to goal setting reflects critiques of the MDGs and the continued 'silos' that prevent joined up policy thinking. It also reflects the move in academia towards adopting an 'intersectionality lens'. So is this a better way forward? The adoption of a standalone gender goal has been the bottom line demand of those lobbying around gender. As such, the SDSN is seemingly out of step with the demands of the wider women's movements, even if by presenting holistic, integrated goals for a joined up agenda, it may actually be one step ahead.

\section{The shifting gender agenda}

While the SDSN goals fed into the HLP goals, ultimately it was the OWG set of goals that the Secretary General took as the basis for his synthesis report. A comparison of the HLP and OWG goals show some winners and some losers in gender terms. The gender goal - in the OWG goals this is Goal 5 - sees a continued ambitious agenda being set. In terms of winners, the addition of a target focused on unpaid care and domestic work (Target 5.4) was largely welcomed, although the construction of the target is somewhat problematic. More generally the 
critique might be that the targets, with demands such as 'end all forms of discrimination against all women and girls everywhere' (Target 5.1), seem more long-term ambitions than realistic aims. It is hard to see what would drive the fundamental changes in society that fulfilling this target would demand. One driver might be having indicators that go further than standard measures based on legal and political frameworks and service provision, and that also measure process as much as outcomes.

How to measure advancements in the goals is an ongoing discussion. Discussions within the SDSN are illustrative of wider debates. Those that favour a more 'business as usual' approach to indicators highlight how many countries struggle to collect even basic data around income poverty, questioning how they could then manage to collect the data necessary for any multidimensional measures of wellbeing. However, the discussion is not only about how to measure, but what to measure. For example, the official SDSN document sees indicators on VAWG focused on law and enforcement, while TG03 had wanted a focus on perceptions of violence and changes in social norms and attitudes. The latter are not only more difficult to measure - the reason used to justify their non-inclusion but also seek to measure social processes rather than just outcomes. They also suggest that a more fundamental change is needed to fulfil the target than expected by the former.

The main loser in the move from the HLP to the OWG goals is, perhaps not surprisingly, sexual and reproductive health and rights. A review of how the language around sexual and reproductive rights has evolved is informative. In the Rio+20 outcome document the language stops short of recognising women's sexual and reproductive rights, instead stating 'sexual and reproductive health and the promotion and protection of all human rights in this context'. In the MDG Summit's review of the MDGs it is interesting that it is mentioned at all since sexual and reproductive health rights were excluded from the MDGs. While discussed in the summit review the discourse is still limiting, as here it is not expressed as sexual and reproductive rights but rather the right to sexual and reproductive health. The HLP has the strongest statement - in keeping with the desire for an ambitious starting point - as it uses the phrase 'ensuring sexual and reproductive health and rights'. By the OWG there had been a small but important change to the language. The OWG goals states that the aim is to 'ensure universal access to sexual and reproductive health and reproductive rights'. Thus the words 'sexual' and 'rights' have been decoupled and the rights agenda then confined to reproductive rights. Interestingly, the text notes that this is 'as agreed in accordance with the Programme of Action of the ICPD and the BPfA and the outcome documents of their review conferences', seemingly using these in a 'limiting' capacity or to mark the boundaries of the rights agenda rather than to expand them.

\section{Also interesting in this context is the SDSN} conceptualisation of sexual and reproductive health and rights (SRHR). While all of the above discourses place SRHR within a health context, the SDSN locates SRHR within a sustainability discourse. The first draft of the SDSN illustrative goals in May 2013 saw Goal 2 - to achieve development within planetary boundaries - include a suggested target of 'rapid voluntary reduction of fertility in countries with total fertility rates above [3] children per woman'. By the June version this had been expanded to state 'rapid voluntary reduction of fertility through the realisation of sexual and reproductive health rights in countries with total fertility rates above [3] children per woman and continuation of voluntary fertility reductions in countries where fertility rates are above replacement level'. Such a construction sees the fulfilment of SRHR as a means to achieve a wider goal, not a goal in itself. It harks back to ideas of 'overpopulation' as being 'to blame' for environmental degradation. Inherent within such statements is the suggestion that those women who continue to have large families are to blame for environmental degradation and the uncertain future of the planet. While promoted by the SDSN leadership, it is not a discourse that sat easily with some of the thematic groups and highlights that marrying development and sustainability, and those that work around them, is not a straightforward task.

While moving mention of SRHR from Goal 2 to a different goal was not achievable, the SDSN leadership did agree some amendments to the language of the target. This highlights how only a small, almost unnoticeable, change in language or the ordering of words, can bring a big change in meaning. It is interesting that the tracked changes to this and other targets is available on the SDSN website - highlighting a clear transparency in what changes have been made, if not an explanation of why (see SDSN 2014). The proposal for the revised target reversed the order of the sentence putting 'realise sexual and reproductive health and rights' first, thus establishing it as an aim in itself. To reinforce this it included the word 'and' to effectively separate rights 
fulfilment from the proposed promotion of the 'rapid reduction in fertility to replacement level or below through exclusively voluntary means'. It removed any mention of targeting specific women. The suggestion that the promotion of rights should be stated as 'for all' was not actively declined, but this does not appear in the May 2014 version of the goals. The inclusion of the word 'informed' when discussing the reduction in fertility was not agreed, since pursuing reductions in fertility through 'exclusively voluntary means' was said to imply that consent is 'informed'. Implied or not, including the word 'informed' would, of course, suggest the need for specific educational activities as a part of the means to achieve the target. It is interesting that once again the international agreements around SRHR were used in the supporting text, here to justify this rather neo-Malthusian approach, with the document referencing the ICPD as also recognising the inter-linkages between lack of reproductive health and rights, high fertility, and the prospects for sustainable development'.

The gender discourse of the post-2015 agenda when expressed in environmental sustainability contexts then appears to remain a somewhat problematic discourse. However, while the SDSN Goal 2 provides the most specific example of this, there are few other examples to draw on from the HLP or OWG. This is not because the discourse is not problematic elsewhere, but because it does not exist. The review of the OWG goals focused on climate change and environmental issues highlights the lack of a gendered discourse and even inclusion of the call for sex-disaggregated data. This is because the focus of these goals is on the planet, not people, and the issues are, once again then constructed as scientific, gender-neutral concerns. Moreover, while the OWG SDGs have climate-related goals, there is a footnote to the main climate change goal that notes that the UNFCCG remains the main driver of international climate change policy, not the SDGs. Gender has been largely absent in the UNFCGC discourse (see Alston 2013) or when included it is in a form that merely rehearses gender stereotypes (MacGregor 2010), suggesting that little further engendering of the post-2015 agenda will emerge through negotiations at COP21.

While climate change is constructed as not just gender neutral, but even people neutral, the impact of climatic change on people via extreme weather events is predicted to increase. It might then be assumed that the international 'disaster' framework might see a more people-centred and gendered discourse. As the international framework for disaster risk reduction has also undergone review during 2015, it might also be assumed that the sustainable development and disaster risk reduction agendas demonstrate considerable overlap and joined up thinking.

\section{The post-2015 disaster risk reduction agenda: the Sendai Framework}

The international framework for disaster risk reduction - The Hyogo Framework for Action (HFA) - was established in 2005, with an aim to bring about a 'substantial reduction of disaster losses, in lives and in the social, economic and environmental assets of communities and countries'. The HFA supporting documentation highlights the inter-linkages between development and disasters. Although the Millennium Declaration resolved to intensify collective efforts to reduce the number and effects of natural and manmade disasters, in the move from the Declaration to the Development Goals this resolution was lost. However, the need to 'disaster-proof' development has been highlighted by actors such as the UK's Department for International Development who note that disasters can 'wipe out any gains that may have been made through poverty reduction programmes or pro-poor economic growth' (DFID 2004). The argument for 'disaster-proofing' then is very much an efficiency discourse (Bradshaw et al. 2013) and parallels the rationale for the inclusion of women in development as 'smart economics': here highlighting reduction of economic loss through disaster risk reduction (DRR) compared to economic gain through investing in women.

In gender terms, while the HFA process is not aligned to any of the key gendered conventions and international agreements, in the opening section the HFA stated that a gender perspective should be 'integrated into all disaster risk management policies, plans and decision-making processes, including those related to risk assessment, early warning, information management, and education and training'. However, its call to integrate gender into all areas of DRR did not result in gender being integrated even into the HFA itself, and in the remainder of the document gender/women are mentioned only twice. Ten years later, and negotiations around HFA2, now known as the Sendai Framework for Disaster Risk Reduction (Sendai Framework), highlight little change in how gender is understood within the DRR discourse.

The WMG along with UN Women have been seeking to influence the post-2015 DRR process. The bottom line call of gender actors will appear very basic to those engaged with Beijing +20 and 
perhaps make them question how far we have (not) travelled over the last 20 years: a demand for sex-disaggregated data to be collected routinely, covering all areas of disaster loss, as well as all DRR activities. The second call was to have women mentioned as leaders in DRR not just as victims of disasters. There has also been an attempt at every opportunity to lobby for some recognition of VAWG and of women's specific SRHR needs, post-event. The new framework adopted at the World Disaster Conference in March 2015 saw some mentions of the need for sex-disaggregated data, but this was not uniform. There is some recognition that women are more than 'victims' and leadership is mentioned in a number of places. However, the vulnerability discourse remains dominant and the leadership discourse is somewhat problematic; for example, it promotes 'empowering women and persons with disabilities to publicly lead...'. It does include one mention of sexual and reproductive health - under discussion of 'access to basic health care services', and there is no mention of VAWG. Given the lack of any mention of women's rights in the Sendai Framework it is not surprising that it makes no mention of Beijing or the ICPD. If the SDGs are over-ambitious to the point of being mere rhetoric, gender rhetoric is yet to enter the Sendai discourse.

There is one standalone statement on women under the 'role of stakeholders'. The original point was critiqued for presenting women as a resource to be used for DRR. Lobbying did lead to some change in language and the second reiteration saw some improvement, but this stopped short at accepting the WMG's suggestion of the need to ensure that the 'critical role of women in managing disaster risk' was 'recognised and valued'. Inclusion of the statement 'including through the provision of resources' was also not accepted and the Sendai Framework standalone gender statement reads:

Women and their participation are critical to effectively managing disaster risk and designing, resourcing and implementing gender-sensitive DRR policies, plans and programmes; and adequate capacity building measures need to be taken to empower women for preparedness as well as build their capacity for alternate livelihood means in post-disaster situations.

Women then are constructed as a resource for DRR. While the need to resource women's preparedness initiatives is implicitly accepted via 'capacity building', the fact that this is discussed in relation to 'alternate livelihoods' post-event suggests an economic efficiency not an equality approach. Thus the policy rhetoric echoes that of 'engendering development', placing women at the service of the DRR policy agenda, rather than served by it and suggesting a further feminisation of obligation and responsibility (see Bradshaw 2010; Chant 2008; Molyneux 2006).

While the gender rhetoric may be borrowed from the development field, disasters and development post-2015 appear to remain separate issues. The need for including DRR as part of the post-2015 development agenda has been recognised by a number of actors and actions ranging from the UN General Assembly Resolution on Sustainable Development to the Intergovernmental Panel on Climate Change, yet there has been little alignment in either direction. The Sendai Framework notes the need to manage the risk of disasters while 'promoting and protecting all human rights, including the right to development'. This is the only mention of rights in the document. It also stresses that 'disaster risk reduction is essential to achieve sustainable development'. This rhetoric echoes that of the post-2015 development agenda whereby the SDGs do include DRR, but not as a goal but as a measure of 'success' in other goals. It constructs a reduction in disaster losses as a measure of 'development' or DRR as a development 'enabler', paralleling the engendering as efficiency discourse.

Although this might all seem very abstract, how disasters and development are conceptualised in international policy frameworks matters for women. While the SDGs promise to promote women's rights in 'normal' times the continued separation of development and disasters construct the latter as not 'normal' and thus seemingly outside the promises around women's rights contained in the SDGs - rights not 'promised' in the Sendai Framework. If climate change does, as predicted, increase the number and intensity of 'natural disasters' this conceptualisation of development, disasters and rights could have important implications for the lives of women across the globe.

\section{Conclusions}

The post-2015 sustainable development agenda seeks to marry environmental sustainability and development. The rhetoric of gender equality is clearly visible in the post-2015 development agenda and in the related goals, but the ambitious nature of the targets make their achievement seem an unlikely reality. While there is a standalone gender goal, and sex-disaggregated data is called for in many areas, a notable absence is within the climate and environmental goals, or the 'sustainable' side 
of the sustainable development agenda. While climate change is presented as gender neutral, with a focus on the planet rather than people, a review of the disaster agenda highlights a lack of a gender perspective even when climate change impacts on

\section{References}

Alston, M. (2013) 'Introducing Gender and Climate Change: Research, Policy and Action', in M. Alston and K. Whittenbury (eds), Research, Action and Policy: Addressing the Gendered Impacts of Climate Change, Netherlands: Springer

Bradshaw, S. (2010) 'Feminisation or

De-Feminisation?: Gendered Experiences of Poverty Post-Disaster', in S. Chant (ed.), International Handbook on Gender and Poverty, Cheltenham: Edward Elgar

Bradshaw, S. with J. Castellino and B. Diop (2013) 'Women's Role in Economic Development: Overcoming the Constraints', background paper prepared for the High-Level Panel of Eminent Persons on the Post-2015 Development Agenda, Sustainable Development Solutions Network, United Nations, May, http://unsdsn. org/resources/publications/womens-rolein-economic-development-overcoming-theconstraints (accessed 14 May 2015)

Chant, S. (2008) 'The "Feminisation of Poverty" and the "Feminisation" of Anti-Poverty Programmes: Room for Revision?', Journal of Development Studies 44.2: 165-97

DFID (2004) 'Adaptation to Climate Change: Making Development Disaster-Proof', DFID Key Sheet 06, London: UK Department for International Development people. It suggests that the gender silence within the sustainability discourse is widespread. A gender lens highlights all too clearly how the marrying of the sustainable and development agendas is perhaps only a marriage of convenience.

MacGregor, S. (2010) 'A Stranger Silence Still: The Need for Feminist Social Research on Climate Change', Sociological Review 57.S2: 124-40

Molyneux, M. (2006) 'Mothers at the Service of the New Poverty Agenda: PROGRESA/ Oportunidades, Mexico's Conditional Transfer Programme', Journal of Social Policy and Administration, Special Issue on Latin America 40.4: 425-49

SDSN (2014) Changes Made by the SDSN to Goals and Targets Initially Proposed on 6 fune 2013, UN Sustainable Development Solutions Network, 11 April, http://beta.unsdsn.org/wp-content/ uploads/2014/04/140430-Changes-to-SDSNgoals-and-targets-since-June.pdf (accessed 14 May 2015)

United Nations (2014) The Road to Dignity by 2030: Ending Poverty, Transforming All Lives and Protecting the Planet, Synthesis Report of the UN Secretary-General on the Post-2015 Sustainable Development Agenda, www.un.org/ga/search/ view_doc.asp? symbol=A/69/700\&Lang=E (accessed 13 July 2015)

United Nations (2012) The Future We Want: Outcome Document Adopted at Rio +20, www.uncsd2012.org/ content/documents/ 727The $\% 20$ Future $\% 20$ We $\% 20$ Want $\% 2019 \% 20 J u n e \% 201230$ pm.pdf (accessed 13 July 2015) 